\title{
LA ALTERACION DE TERMINOS MUNICIPALES EN EL NUEVO DERECHO LOCAL (")
}

\author{
por \\ Francisco Sosa Wagner \\ Catedrático de Derecho Administrativo \\ Pedro de Miguel García \\ Profesor Titular de Derecho Administrativo
}

SUMARIO: EL REGIMEN JURIDICO VIGENTE: 1. EL COMIENZO DE LA ETAPA DEMOCRÁTICA Y LA DESCENTRALIZACIÓN DE LA MATERIA: A) El marco constitucional. B) Las determinaciones estatutarias: C) Los Reales Decretos de traspasos. D) La legislación autonómica y la práctica administrativa.-2. EL ARTÍculo 13 DE LA LEY REGULADORA DE LAS BASES DEL RÉGIMEN LOCAL DE 2 DE ABRIL DE 1985: A) Los orígenes del precepto. B) Significado. C) Contenido.-3. LA REGULACIÓN DE LA ALTERACIÓN DE LOS TÉRMINOS MUNICIPALES EN EL TEXTO REFUNDIDO DE 18 DE ABRIL DE 1986 Y EN el Reglamento de Población y Demarcación Territorial de LAS ENTIDADES LOCALES DE 11 DE JULIO DE 1986: A) Significado de esta regulación. B) Los supuestos de alteración. C) Las causas o motivos que pueden dar lugar a la alteración de los términos municipales. D) El procedimiento: a) Iniciación. b) Ordenación e instrucción. c) Resolución. E) La impugnación jurisdiccional. F) La falta de previsión del acomodo de materias complementarias. G) Los enclaves municipales. H) El deslinde de los términos municipales.

(*) Este trabajo constituye uno de los capítulos del libro Creación, supresión y alteración de términos municipales, publicado por el INSTITUTO DE EsTUDIOS DE ADMINISTRACIÓN LOCAL. 


\section{EL REGIMEN JURIDICO VIGENTE}

\section{El COMIENZO DE LA ETAPA DEMOCRÁTICA \\ Y LA DESCENTRALIZACIÓN DE LA MATERIA}

Con la reforma política que tiene lugar a comienzos de 1977, y sin esperar a la aprobación de la Constitución, se pone inmediatamente en marcha el proceso de acomodación del Régimen local al nuevo orden, como consecuencia del cual va a producirse un importante desapoderamiento de la Administración del Estado, que se hará patente desde los primeros momentos, como lo prueba el hecho de que sea la Administración local una de las materias más sensiblemente afectadas por las transferencias en esta inicial etapa preautonómica.

\section{A) El marco constitucional}

La Constitución de 1978, al distribuir verticalmente el poder en tres niveles -estatal, comunitario y local - ha reconocido la existencia de una pluralidad de sistemas de organización diversos, a la par que integrados, cuya configuración y entramado sólo han quedado esbozados en sus grandes líneas maestras.

Esta observación se evidencia particularmente en el caso de la Administración local, a la que sólo se dedican tres preceptos (los artículos 140 a 142) y algunas referencias indirectas en los artículos 148 y 149. De tan exiguo material únicamente puede deducirse que las entidades que integran dicha Administración están dotadas de autonomía para gestionar al ámbito competencial correspondiente a sus intereses, pero no se concreta dicho ámbito, ni se establece un esquema de su organización, ni se articulan sus relaciones con los poderes territoriales superiores, debiendo ser las cámaras legislativas de dichos poderes las que configuren positivamente el régimen de aquellas entidades, y ello tanto en lo competencial (cosa que harán al llevar a cabo sus respectivas funciones legislativas) como en lo estructural y funcional, lo que con carácter básico será hecho por el Estado y en detalle por las Comunidades Autónomas.

El Régimen local no es, como acabamos de ver, una materia unitaria, cuya regulación sea susceptible de ser asignada en bloque al Estado o a las Comunidades Autónomas (por eso la Constitución 
no la incluye de modo exclusivo ni en el artículo 148 ni en el 149), sino un complejo de asuntos que se reparten entre ambas instancias, de tal suerte que ninguna de ellas pueda monopolizar su tratamiento (1). Por ello, y a diferencia de los sistemas federales, como el alemán, en los que las Administraciones locales son piezas organizativas de los Estados miembros, el sistema establecido por nuestra Constitución es claramente «bifronte», como afirmó el Tribunal Constitucional en su Sentencia de 23 de diciembre de 1982, al declarar que «el régimen jurídico de las Corporaciones locales, aun en aquellas Comunidades Autónomas que, como la catalana, asumen el maximum de competencias al respecto, es siempre el resultado de la actividad concurrente del Estado y de las Comunidades Autónomas... que hace imposible calificarlo de forma unívoca como intracomunitario o extracomunitario».

Esta concurrencia competencial va a hacer posible que en lo estructural -aspecto éste que es el que aquí interesa- sea perfectamente compatible el mantenimiento de unos rasgos comunes (responsabilidad que corresponde al Estado al dictar las normas básicas) con la diversificación de regímenes exigida por las peculiares circunstancias de cada territorio (soluciones organizativas de detalle que quedan confiadas a las Comunidades Autónomas).

Esta es la solución armónica dada por la Constitución en sus artículos $149,1,18 .^{\circ}$, y 148, 1, 2. , al atribuir, respectivamente, al Estado «las bases del régimen jurídico de las Administraciones públicas» y a las Comunidades Autónomas «las alteraciones de los términos municipales comprendidos en su territorio y, en general, las funciones que correspondan a la Administración del Estado sobre las Corporaciones locales y cuya transferencia autorice la legislación sobre Régimen local».

A este statu quo se llegó, sin embargo, durante el proceso de tramitación parlamentaria del Proyecto de Constitución, ya que en el Anteproyecto del texto constitucional no había ningún precepto que enumerase las competencias que podían asumir las Comunidades Autónomas en la materia.

En este punto puede ser de interés recordar la trayectoria parlamentaria del citado párrafo $2 .^{\circ}$ del artículo 148,1 , de la Constitución.

(1) Vid. Luciano Parejo Alfonso: Garantia institucional y autonomias locales, Madrid, 1981, págs. 142 y sigs., y Santiago MuÑoz MAchaDO: Derecho público de las Comunidades Autónomas, tomo II, Civitas, Madrid, 1984, págs. 186 y 187. 
El punto de partida hay que situarlo en el informe de la Ponencia, al incluir, como consecuencia del criterio adoptado por mayoría sobre el Título VIII, una Disposición adicional nueva en cuyo número 2 se decía lo siguiente:

«2. Los estatutos de autonomía en aplicación del artículo 139 de la Constitución podrán asumir competencias en las siguientes materias:

b) Las alteraciones de los territorios de las Entidades locales comprendidas en la Región; y, en general, las actividades de aquéllas necesitadas de aprobación superior".

Más tarde, la Comisión de Asuntos Constitucionales, atendiendo diversas enmiendas in voce del Grupo Parlamentario de UCD, acordó convertir en un artículo 139 bis el número 2 de la Disposición adicional del dictamen de la Ponencia, con algunas modificaciones, entre ellas la del apartado b). En el dictamen de la Comisión a dicho artículo 139 bis se le da el número 141, que queda así:

«Artículo 141.1. Las Comunidades Autónomas podrán asumir competencias en las siguientes materias:

b) Las alteraciones de los términos municipales comprendidos en su ámbito y, en general, las funciones que pudieran corresponder a la Administración del Estado, de acuerdo con lo que al respecto establezca la legislación sobre Régimen local».

En el debate del Pleno del Congreso no se presentaron enmiendas a dicho artículo, que fue aprobado con 264 votos a favor, dos en contra y quince abstenciones, y su texto no sufrió alteraciones en el Proyecto de Constitución que aprobó el Pleno en la sesión de 21 de julio de 1976.

Trasladado el Proyecto al Senado, la Comisión de Constitución, en el debate de las enmiendas al texto, rechazó una enmienda del Grupo Vasco que proponía suprimir la última frase, por la siguiente: «... que pudieran corresponder a la Administración del Estado en materia de Régimen local», y aprobó una enmienda in voce de UCD, dándole al precepto -aunque bajo el nuevo núm. 146, 1, b) la redacción que resultaría definitiva en el actual artículo 148, 1, 2.a , al ser respetados sus términos por el Pleno del Senado, primero, y después por el dictamen de la Comisión Mixta Congreso-Senado. 


\section{B) Las determinaciones estatutarias}

Prácticamente la totalidad de los Estatutos de Autonomía han asumido competencias en materia de alteración de términos municipales, de acuerdo con las previsiones constitucionales del artículo $148,1,2 .^{a}(2)$.

Navarra no ha gozado de ningún régimen especial en esta materia, y el propio artículo 46 del Reglamento de Administración municipal de Navarra señala que la creación y alteración de términos municipales se rige por la legislación general, por lo que debe entenderse atribuida dicha competencia a la Comunidad Autónoma en virtud de lo dispuesto en el artículo $141,1, b$ ).

En el País Vasco, de una forma ciertamente confusa, se atribuye a la Comunidad Autónoma (art. 10,1) la competencia exclusiva sobre las demarcaciones territoriales municipales, sin perjuicio de las facultades de los Territorios Históricos, que disponen asimismo de la misma competencia exclusiva en materia de demarcaciones territoriales de ámbito supramunicipal que no excedan los límites provinciales. A tenor de este reparto, creemos que todo lo que es alteración de términos municipales, en el sentido que está siendo estudiado en este libro, corresponde a las Comunidades Autónomas, pues los Territorios Históricos contraen sus competencias a las del ámbito supramunicipal (las Comarcas, Areas Metropolitanas y Mancomunidades de Municipios, según la legislación básica estatal), que no excedan del ámbito territorial de la Provincia o Territorio Histórico.

Surge así una contradicción con la Ley Reguladora de las Bases del Régimen local de 2 de abril de 1985, que atribuye, en sus artículos 42 y siguientes, tales competencias a las Comunidades Autónomas, incluso para el supuesto de las Areas Metropolitanas, en que se exige una ley. Tal contradicción hay que salvarla aplicando la Disposición adicional segunda, 2, de la citada Ley básica, a cuyo tenor «los Territorios Históricos de Alava, Guipúzcoa y Vizcaya ejercerán las competencias que les atribuyen el Estatuto Vasco y la legislación interna de la Comunidad Autónoma que se dicte en

(2) Vid. artículos 11, a), Asturias; 22, 2, Cantabria; 9, 1, La Rioja; 11, a), Murcia; 31, 8, Comunidad Valenciana; 13, 3, Andalucía; 35, 2, Arag6́n; 31, 1, CastillaLa Mancha; 27, 2, Galicia; 29, 2, Canarias; 8, 2, Extremadura; 26, 2, Madrid; 27, 8, Castilla-León, y 10, 2, Baleares, atribuyendo el artículo 39, 1, la función ejecutiva y la gestión a los Consejos Insulares. 
su desarrollo y aplicación, así como las que la presente Ley asigne con carácter general a las Diputaciones provinciales».

\section{C) Los Reales Decretos de traspasos}

Iniciada ya antes de la constitución de las Comunidades Autónomas la práctica de la transferencia de funciones a una buena parte de los Entes preautonómicos, y extendida y generalizada definitivamente dicha práctica una vez que quedaron aprobados los correspondientes Estatutos, las Comunidades Autónomas se han convertido así en las Administraciones competentes para la iniciación de oficio de los expedientes de alteraciones de términos municipales, la segregación de parte de un Municipio para agregarse a otro limítrofe y la ordenación, instrucción, informe y resolución de los expedientes de alteración de términos municipales que supongan la creación o supresión de Municipios.

Este es el modelo que, con carácter general, deriva de los correspondientes Reales Decretos de traspasos (3), a salvo de algunas matizaciones poco relevantes, como es el caso de Cataluña y el País Vasco, que sólo recibieron el primer traspaso -iniciación de oficio de los expedientes de alteración de términos municipales- y rechazaron los restantes por entender que tenían asumidas tales competencias en el Estatuto y que, por tanto, eran innecesarios aquéllos.

(3) Vid. Real Decreto de 25 de agosto de 1978 (País Vasco); Real Decreto de 26 de julio de 1978 (Cataluña); Reales Decretos de 13 de febrero de 1979, de 24 de julio de 1982 y de 28 de diciembre de 1983 (Galicia); Reales Decretos de 13 de febrero de 1979 y de 20 de julio de 1983 (Andalucía); Reales Decretos de 24 de julio de 1982 y de 28 de diciembre de 1983 (Principado de Asturias); Reales Decretos de 24 de julio de 1982 y de 1 de septiembre de 1983 (Cantabria); Real Decreto de 25 do agosto de 1983 (La Rioja); Reales Decretos de 29 de febrero de 1980, de 24 de julio de 1982 y de 28 de diciembre de 1983 (Región de Murcia); Reales Decretos de 13 de febrero de 1979 y de 25 de agosto de 1983 (Comunidad Valenciana); Reales Decretos de 13 de febrero de 1979 y de 24 de julio de 1982 (Aragón); Reales Decretos de 29 de diciembre de 1981, de 24 de julio de 1982 y de 28 de diciembre de 1983 (Castilla-La Mancha); Reales Decretos de 7 de diciembre de 1979, de 24 de julio de 1982 y de 25 de agosto de 1983 (Canarias); Reales Decretos de 21 de diciembre de 1979, de 24 de julio de 1982 y de 28 de diciembre de 1983 (Extremadura); Reales Decretos de 7 de septiembre de 1979, de 24 de julio de 1982 y de 28 de diciembre de 1983 (Islas Baleares); Real Decreto de 20 de julio de 1983 (Madrid), y Reales Decretos de 29 de diciembre de 1981 , de 24 de julio de 1982 y de 25 de agosto de 1983 (Castilla-León). 


\section{D) La legislación autonómica y la práctica administrativa}

Hasta el momento, la actividad desarrollada por las Comunidades Autónomas en la materia no puede decirse que sea verdaderamente espectacular.

En lo legislativo aún no han sido dictadas las normas de detalle reguladoras de los respectivos Regímenes locales, y sólo es posible encontrar ocasionalmente alguna disposición legal que indirectamente aluda o haga relación al tema que nos ocupa, como sucede, por ejemplo, con la Ley de Andalucía 3/1983, de 1 de junio, de Organización Territorial de la Comunidad Autónoma, que en su artículo 5..$^{\circ}$ se limita a anunciar una Ley (aún no dictada) que fijará los requisitos y procedimientos de alteración de términos municipales y fusión de Municipios limítrofes, o la Ley de la Generalidad de Cataluña 12/82, de 8 de octubre, por la que se regula el procedimiento para el cambio de nombre de los Municipios de Cataluña.

La práctica administrativa, sin que resulte tampoco exagerada, es, no obstante, algo más dinámica, por lo menos en algunas Comunidades Autónomas.

Tomando como período de tiempo el transcurrido desde la creación de las Comunidades hasta comienzos de 1986 nos encontramos con los siguientes datos. En Madrid y Cantabria no se había tramitado ni un solo expediente relativo a la creación o supresión de Municipios o a la alteración de términos municipales. En Asturias, Navarra y Canarias se encontraban en tramitación algunos expedientes de segregación para incorporación a otros Municipios o para su conversión en otros nuevos (4). En Murcia se crearon tres nuevos Municipios por segregación, pero las resoluciones resultaron impugnadas (5). En Galicia se habían resuelto un expediente de segregación y otro de deslinde y se encontraban en trámite tres de segregación y uno de deslinde (6). En el País Vasco se habían re-

(4) En Asturias se estaba tramitando la parroquia de Santa María de Sisterna para su incorporación al Concejo de Degaña; en Navarra varios Concejos importantes (Beriaín, Berriozar, Noaín) estaban preparando expedientes para su conversión en Ayuntamientos, y en Canarias se encontraba en tramitación la segregación de la zona de la Caldereta, perteneciente al término de Breña Alta (La Palma), para su agregación al de Santa Cruz de la Palma, y la segregación de las zonas de Barranco de Juncalillo, Barranco Hondo Arriba y Barranco Hondo Abajo, pertenecientes al término de Galdar (Gran Canaria), para su agregación al de Artenara.

(5) Los Municipios de nueva creación fueron Los Alcázares, formado por segregación de los términos de San Javier y Torre Pacheco, Puerto Lumbreras, por segregación de Lorca, y Santomera, por segregación de Murcia.

(6) Los expedientes resueltos son el de segregación de siete parroquias de $\mathrm{Ca}$ - 
suelto cuatro expedientes de segregación de núcleos de población para constituirse en nuevos Municipios (7). En Castilla-León se habían producido dos segregaciones de núcleos de población y dos disoluciones de Municipios para su incorporación a Municipios limítrofes (8). En Castilla-La Mancha se habían aprobado cuatro segregaciones (dos para constituir nuevos Municipios y dos para su agregación a otros) y una alteración de términos municipales, encontrándose en tramitación cuatro nuevos expedientes de segrega. ción (9). En Baleares se había aprobado la segregación de una Entidad local menor para la constitución en Municipio independiente (10). En La Rioja se había aprobado la segregación de un núcleo para su agrupación a otro Municipio (11). En Valencia, por último, se habían resuelto un expediente de modificación de términos y uno de segregación y se encontraban en tramitación otros tres de modificación, uno de traslado y dos de segregación (12).

Los datos expuestos son suficientemente ilustrativos de la existencia de un doble hecho: por un lado, la escasa actividad adminis-

pela para su agregación a As Pontes de García Rodríguez, y el deslinde de los términos municipales de Poio y Pontevedra. Los de trámite son el de segregación de las parroquias de Quereño y Villardegeos para su agregación a Carballeda de Valdeorras; el de segregación en Santiago de las parroquias de Barciela y César para su agregación a Osoro; la segregación de varias parroquias de Ortigueira para constituir un Municipio independiente con capitalidad en Cariño, y el deslinde de los términos municipales de Sarria e Incio entre las parroquias de Vilademuros y Froilán.

(7) Se constituyeron en Municipios los siguientes núcleos de población: Loiu, Sondika, Derio, Zamudio, Erandio, Berriatúa, Mendazo y Lasarte-Oria (vid Decretos 220/82, de 20 de diciembre; 258/83, de 21 de noviembre; Norma Foral 1/86, de 31 de enero).

(8) Se segregaron los núcleos de población de Abelón, perteneciente a Peruela, y la Entidad Local Menor de Paradela del Río, perteneciente a Corullon, para su incorporación respectiva a Moral de Sayago y Villadecanes-Toral de los Vados, y se disolvieron los Municipios de Castil de Carrias y Fornillos de Fermoselle para su incorporación respectiva a los Municipios de Belorado y Villar del Buey (vid. Orden de 31 de diciembre de 1983; Decreto 129/84, de 5 de diciembre; Decreto 50/85, de 16 de mayo, y Decreto $87 / 85$, de 31 de julio).

(9) Se segregaron de Almodóvar de Monterrey para constituirse en nuevos Municipios los núcleos de Almodóvar del Pinar, Olmeda del Rey, Solera de Gabaldón, Chumillas y Monteagudo de las Salinas. Asimismo se segregaron núcleos de Cuenca para su agregación a Majadas y Vega del Codorno (vid. Decreto 152/83, de 20 de septiembre; Decreto 23/85, de 5 de marzo; Decreto 24/85, de 5 de marzo; Decreto $80 / 85$, de 3 de septiembre, y Orden de 22 de febrero de 1985).

(10) Entidad Local Menor de Ariany, perteneciente al Municipio de Petra (vid. Decreto 2622/82, de 30 de julio).

(11) Segregación de una porción del término municipal de Logroño para su agregación al de Agoncillo (vid. Decreto 3/85, de 15 de febrero).

(12) La modificación de términos fue la de los Municipios Aspe-Elche y la segregación la de Alquerías del Niño Perdido, refiriéndose los expedientes en tramitación a Pincaya y Torrent, Sagunto-Almenara y Masamagrell-Masalpasar (modificación de términos), Domeño (traslado), Pilar de la Horadada y San Juan de Moro (segregación de Orihuela y de Villafarnés, respectivamente). 
trativa realizada en orden a la confección de un nuevo mapa municipal más acorde con las exigencias impuestas por la eficacia en la gestión de los asuntos públicos confiados a los Ayuntamientos, y, por otro, el enorme predominio de la tendencia segregadora sobre la de fusión: hechos ambos que no se avienen con la política declarada en el artículo 13 de la Ley Reguladora de las Bases del Régimen local de fomentar la fusión de Municipios con el fin de mejorar la eficacia de las Corporaciones locales.

\section{El artículo 13 de la ley Reguladora de las Bases}

DEL RÉGIMEN LOCAL DE 2 DE ABRIL DE 1985

\section{A) Los origenes del precepto}

En el Proyecto que el Gobierno presentó a las Cortes en marzo de 1984 se confiaba la materia a las Comunidades Autónomas, si bien con el establecimiento de ciertas garantías de carácter político, jurídico y económico.

En efecto, el artículo 13 del citado Proyecto decía textualmente:

«1. La creación o supresión de Municipios, así como la alteración de términos municipales, se regulará por la legislación de las Comunidades Autónomas sobre Régimen local. Requerirán en todo caso audiencia de los Municipios interesados y dictamen del Consejo de Estado.

2. La creación de nuevos Municipios sólo podrá realizarse sobre la base de núcleos de población territorialmente diferenciados y siempre que los Municipios resultantes cuenten con recursos suficientes para el cumplimiento de las competencias municipales y no suponga disminución en la calidad de los servicios que venían siendo prestados".

Como consecuencia de las discusiones habidas en el Congreso, y en especial de las provocadas por las enmiendas de los Grupos Parlamentarios del Partido Nacionalista Vasco y de la Minoría Catalana, al primer apartado del precepto se le añadió el siguiente texto: "o del órgano consultivo superior de los Consejos de Gobierno de las Comunidades Autónomas, si existiese. Simultáneamente a la petición de este dictamen se dará conocimiento a la Administración del Estado".

Posteriormente, en el Senado, y a propuesta del Grupo Parlamentario Socialista, el precepto recibe la adición de un tercer apartado del siguiente tenor: "Sin perjuicio de las competencias de las 
Comunidades Autónomas, el Estado, atendiendo a criterios geográficos, sociales, económicos y culturales, podrá establecer medidas que tiendan a fomentar la fusión de Municipios, con el fin de mejorar la capacidad de gestión de los asuntos públicos locales», con lo que el texto adquiere la redacción definitiva que habría de figurar en la vigente Ley de 2 de abril de 1985.

\section{B) Significado}

Este precepto incorpora a la legislación de desarrollo de la Constitución la trascendente innovación que supone la atribución a la legislación autonómica de la competencia para regular la supresión y creación de nuevos Municipios, así como la alteración de términos municipales. De acuerdo con el contenido de la Constitución y de los Estatutos de Autonomía aprobados antes de la promulgación de la legislación básica, que hemos visto en los capítulos anteriores, la Ley básica no incorpora, pues, ninguna novedad en este punto. Es esta una materia, pues, de la plena disponibilidad para el legislador autonómico, que sólo se encuentra vinculado por los criterios materiales, mínimos, como veremos, que incorpora el artículo $13 \mathrm{y}$ por los trámites procedimentales contenidos igualmente en dicho precepto. Todo ello por el carácter básico que la Ley tiene en su integridad, y que deriva del título constitucional que al Estado otorga el artículo 149, 1, 18, de la Constitución (que le permite regular el régimen jurídico básico de las Administraciones públicas), y de acuerdo con el concepto de bases que el Tribunal Constitucional ha perfilado, según el cual por bases hay que entender los criterios generales de regulación de un sector del Ordenamiento jurídico o de una materia jurídica, que deben ser comunes a todo el Estado (Sentencia de 7 de abril de 1983).

Por ello la Disposición adicional primera de la Ley Reguladora de las Bases del Régimen local, al incluir a las Comunidades Autóno. mas de Asturias, Cantabria, Rioja, Murcia, Aragón, Castilla-La Mancha, Castilla-León, Baleares, Extremadura y Madrid entre aquellas que deberán ejercer sus competencias legislativas en el marco de lo establecido en el artículo 13, debe interpretarse como un precepto destinado a precisar cuáles son las materias que de acuerdo con sus Estatutos pueden ser objeto de desarrollo legislativo por aquellas Comunidades Autónomas, que tienen sus competencias en materia de Régimen local contraídas, a «las que se conectan con las materias 
enumeradas en el artículo 148, 1, 2, precepto éste que, como se sabe, presta cobertura a las competencias asumidas en sus respectivos Estatutos por esas Comunidades Autónomas». No debe, pues, interpretarse como una exclusión de aquellas Comunidades Autónomas no citadas expresamente, en aplicación de la regla «inclusio unius, exclusio alterius»: las limitaciones materiales y procedimentales contenidas en el artículo 13 vinculan a las demás Comunidades Autónomas no citadas que, por imperativo constitucional, y aunque hayan asumido la materia como exclusiva, tendrán siempre el techo de la legislación básica del Estado, dictada, como ha quedado dicho, en aplicación del título competencial contenido en el artículo $149,1,18$. (Ninguna singularidad existe para Navarra, cuyo Reglamento de Administración municipal de 1928 remite las alteraciones de términos municipales a la legislación local general).

\section{C) Contenido}

La redacción del precepto permite sustantivar la creación y supresión, por un lado, y la alteración de términos municipales, por otro. Se gana así en firmeza en cuanto al sentido que debe alcanzar la legislación de desarrollo de las Comunidades Autónomas, que puede distinguir la simple alteración de términos municipales, concebida como una operación particular, de la creación o supresión de Municipios (que exige alterar términos), pero que es concebible como operación globalizadora, es decir, de carácter general, sobre el territorio de la Comunidad Autónoma. Hay, a nuestro juicio, por tanto, diseñado en embrión, un sistema que permitirá distinguir en la legislación de desarrollo de las Comunidades Autónomas dos materias: una sería la regulación general, por ley, del procedimiento y requisitos para alterar singularmente territorios municipales que por su extensión, población, etc., hayan devenido inadecuados; otra consistiría en la aprobación, también por ley, de un diseño general que no se limitara a afrontar la singularidad de supuestos concretos, sino que dibujara una amplia operación reformadora que afectara al territorio entero de la Comunidad Autónoma o a partes sustantivas y destacadas del mismo. Ambos contenidos no sólo son posibles, sino que están claramente apuntados por el legislador de 1985. Es decir, la cirugía sobre el territorio puede operarse a pequeña escala a través de la aprobación de expedientes concretos, o a gran escala, mediante leyes que, respetando el contenido básico del artículo 13, procedan a un nuevo trazado del mapa municipal. 
Por su parte, el criterio material exigido para la creación de nuevos Municipios supone una corrección relevante del sistema anterior. Se exige, en efecto, la existencia de núcleos territorialmente diferenciados, lo que se corresponde con el antiguo requisito de población y territorio, pero se sustituye el concepto, periclitado, de riqueza imponible por el más moderno y omnicomprensivo de recursos suficientes para el cumplimiento de las competencias municipales, y no sólo para sostener los servicios municipales obligatorios. El artículo 13 quiere, con ello, ampliar la suficiencia de recursos al cumplimiento y ejecución de todas las competencias que la Ley estatal o de la Comunidad Autónoma, según el sistema constitucional de distribución de competencias, atribuye a los Municipios, y no sólo a aquellos servicios considerados obligatorios por el artículo 26 de la Ley Reguladora de las Bases del Régimen local. Por último, no puede ser disminuida la calidad de los servicios que venían siendo prestados de acuerdo con el anterior diseño municipal, lo cual supone que el legislador básico ha establecido un criterio abiertamente más restrictivo para la creación de nuevas Entidades municipales que el manejado por el legislador precedente, que deberá ser tenido en cuenta no sólo por la legislación de las Comunidades Autónomas, sino también, y muy destacadamente, por los Tribunales de Justicia en la solución de los innumerables conflictos judiciales en que, a menudo, desembocan estas operaciones.

Desde la perspectiva procedimental, algunas innovaciones es necesario realizar: la audiencia a los Municipios interesados y el dictamen del Consejo de Estado estaban ya en la legislación hoy derogada. Sólo que, en la actualidad, tienen un carácter básico, por lo que, en rigor, debe ser respetado por el legislador autonómico, pero también puede ser completado o aumentado por éste. En todo caso, la audiencia, sumariamente regulada en el Reglamento, exige hoy concreciones que son contenido insoslayable de la legislación autonómica: Organo que debe llevarla a cabo; plazo; que no debe configurarse con carácter rígido y que debe repetirse cuantas veces se incorporen aspectos nuevos sustanciales en el expediente; valor del pronunciamiento de las poblaciones afectadas; momento procedimental en que procede; derecho a información sobre los planes generales al respecto de la Comunidad Autónoma; etcétera:

El dictamen del Consejo de Estado deberá solicitarse a través del Ministerio de Administración Territorial (art. 48 de la Ley Reguladora de las Bases del Régimen local), hoy Ministerio para las 
Administraciones Públicas (de acuerdo con el Real Decreto 1519/ 1986, de 25 de julio); el plazo que el Alto Cuerpo tiene para evacuar tal dictamen será normalmente el de dos meses, de acuerdo con el Reglamento del Consejo de Estado (Real Decreto 1674/1980, de 18 de julio, art. 128). Si existe órgano consultivo en la correspondiente Comunidad Autónoma será su legislación reguladora la que aclare estas cuestiones. La puesta en conocimiento de la petición de dictamen, que la Ley exige se haga «a la Administración del Estado», hay que entender hoy que debe ser hecha al Ministerio para las Administraciones Públicas, al tener éste atribuidas las competencias relativas a la preparación y ejecución de la política del Gobierno en relación con las Comunidades Autónomas y las Corporaciones locales (art. 3. ${ }^{\circ}$ del Real Decreto citado).

El párrafo tercero de este artículo 13 completa, a nuestro juicio, el pensamiento del legislador, que tiene puesta la vista en operaciones destinadas a la supresión de Entidades municipales, ya que el Estado se reserva la posibilidad de «establecer medidas que tiendan a fomentar la fusión de Municipios con el fin de mejorar la capacidad de gestión de los asuntos públicos locales", lo que, por cierto, ha sido contestado por alguna Comunidad Autónoma, impugnante en la forma que veremos.

El objeto, pues, es conseguir la fusión de Municipios, imperativo derivado de la realidad municipal española que cabalmente exige la reducción del número de Municipios como uno de los medios para alcanzar la mejora de "la capacidad de gestión de los asuntos públicos locales». Las medidas a dictar pueden ser de muy variado carácter - aunque inevitablemente con un contenido económicoy proceden tanto del Estado como de las propias Comunidades Autónomas (de ahí el «sin perjuicio» con que se abre el párrafo).

\section{LA REGULACIÓN DE LA ALTERACIÓN DE LOS TÉRMINOS} MUNICIPALES EN EL TEXTO REFUNDIDO DE 18 DE ABRIL DE 1986 Y en el Reglamento de Población y Demarcación Territorial DE LAS ENTIDADES LOCALES DE 11 DE JULIO DE 1986

\section{A) Significado de esta regulación}

El Texto Refundido, por imperativo de la propia técnica de la refundición, comprende la regularización, aclaración y armonización de las disposiciones con rango de Ley anteriores a la aprobación de 
la Ley Básica (Disposición final primera, primer párrafo); el Reglamento, por su parte, de acuerdo también con lo dispuesto por la Ley Básica (Disposición final primera, párrafo segundo), se actualiza y acomoda a la norma básica. En consecuencia, el legislador tanto del Real Decreto legislativo 781/1986 como del Real Decreto. 1690/1986, de 11 de julio, ha aprovechado en una materia comoesta, sólo ligeramente afectada por el contenido del artículo 13, para poner orden en la confusa situación precedente y, en consecuencia, aclarar el régimen de la alteración de los términos municipales, dejando intacta, por ello, la otra vía que hemos visto abre el artículo 13, y que habría de ser abordada por la legislación en cada Comunidad Autónoma.

En cualquier caso, toda esta regularización tiene carácter supletorio para las Comunidades Autónomas que pueden proceder a su modificación, sin más limitaciones que las explicadas supra. Así lo establece con claridad la Disposición final séptima, $1, a$ ), del Texto Refundido, que sólo otorga la condición de básica y, por tanto, no modificable por la legislación de desarrollo, al artículo $2 .^{\circ}$ («cada Municipio pertenece a una sola Provincia») y al artículo $3 .^{\circ}, 2$ ("en ningún caso la alteración de términos municipales podrá suponer modificación de los límites provinciales»), ambos como consecuencia de los preceptos constitucionales sobre los límites territoriales. provinciales que veremos más adelante (13).

\section{B) Los supuestos de alteración}

Cuatro son los previstos por los artículos $3 .^{\circ}$ del Texto Refundido y $2 .^{\circ}$ del Reglamento: a) la incorporación de uno o más Municipios a otro u otros limítrofes; b) la fusión de dos o más Municipios limítrofes; c) la segregación de parte del territorio de uno o

(13) La posibilidad de incorporar materias básicas en un Texto Refundido está. respaldada por la Jurisprudencia constitucional, que no ha dudado en admitirlas en normas incluso de rango inferior. En efecto, el Tribunal Constitucional ha pasado de la defensa del exclusivo monopolio parlamentario en la tarea de definir las bases (Sentencia de 28 de julio de 1981), a la aceptación de la excepción a este monopolio. Así, la Sentencia de 28 de enero de 1982, que admite que el Gobierno pueda realizar provisionalmente tal tarea cuando la materia esté regulada por normas preconstitucionales no incompatibles con la Constitución; la de 28 de abril de 1983, que permite al Reglamento regular aspectos básicos que completen el contenido de la Ley; en fin, las de 11 de junio de 1984,9 de octubre de 1984, 19 de octubre de 1984 y 25 de enero de 1985, que reconocen como básicas meras normas reglamentarias como consecuencia del concepto material de bases. En la doctrina puede verse GARCfA DE ENTERRfA: Estudios sobre autonomias territoriales, Madrid, 1985, págs. 325 y siguientes. Y también Santiago MuÑ̃z Machado: Derecho público..., cit., I, págs. 421 y sigs. 
varios Municipios para constituir otro independiente; d) la segregación de parte del territorio de un Municipio para agregarlo a otro limítrofe.

Veamos el régimen jurídico de cada uno de estos supuestos.

\section{C) Las causas o motivos que pueden dar lugar a la alteración de términos municipales}

El supuesto del apartado a) del artículo 3. del Texto Refundido («incorporación de uno o más Municipios a otro u otros limítrofes») procede "solamente... cuando se den notorios motivos de necesidad o conveniencia económica o administrativa». El Reglamento, sin embargo, suprime el adverbio «solamente» $\mathrm{y}$, además, añade otra causa, "cuando lo imponga la mejora de la capacidad de gestión de los asuntos públicos locales». La dicción de este precepto incluye tanto la incorporación forzosa, acordada por la Comunidad Autónoma en la forma prevista en este Reglamento (o en la que, en su caso, disponga su legislación reguladora), como la incorporación voluntaria, acordada por los Municipios y ratificada posteriormente por el acuerdo del órgano correspondiente de la Comunidad Autónoma.

El Consejo de Estado, en su Dictamen de 25 de junio de 1986 (Expediente núm. 48.863), no hace ninguna observación a esta ampliación, que, sin embargo, sí realiza al artículo siguiente, referido a la fusión. En efecto, según el artículo $5 .^{\circ}$ del Texto Refundido, procede ésta: a) cuando, separadamente, carezcan de recursos suficientes para atender los servicios mínimos exigidos por la Ley; b) cuando se confundan sus núcleos urbanos como consecuencia del desarrollo urbanístico; c) cuando existan notorios motivos de necesidad o conveniencia económica o administrativa. Pues bien, el texto enviado por el Gobierno a dictamen incluía un párrafo $d$ ) que acogía como causa de fusión "cuando ésta sea necesaria para la mejora de la capacidad de gestión de los asuntos públicos locales", que hubo de ser suprimida porque, según el Consejo de Estado, «resulta conceptualmente difícil la delimitación del concepto así formulado en relación con el que aparece en el párrafo c) precedente ('cuando existan notorios motivos de necesidad o conveniencia económica o administrativa'); por otra parte, aquel supuesto no se incluye en el Texto Refundido de Régimen local aprobado por Real Decreto legislativo 781/1986, de 18 de abril (art. 5..$^{\circ}$ ), aunque el ar- 
tículo 13, 3, de la Ley de Bases 7/1985, de 2 de abril, habilita al Estado, sin perjuicio de las competencias de las Comunidades Autónomas, para establecer medidas de fomento que estimulen a fusionar Municipios con el fin de mejorar la capacidad de gestión de los asuntos públicos locales».

Esta argumentación del Alto Cuerpo consultivo resulta poco convincente. El Reglamento no desarrolla el Texto Refundido, sino la Ley Básica, que obliga a «acomodar a lo dispuesto en la misma todas las normas reglamentarias» (Disposición final primera, párrafo segundo, de la Ley Reguladora de las Bases del Régimen local), por lo que en esta materia en la que el legislador anuncia con carácter básico el fomento de la fusión «con el fin de mejorar la capacidad de gestión de los asuntos públicos locales», es evidente que constituye imperativo de la acomodación un párrafo de las características del propuesto por el Gobierno. Este criterio del Consejo de Estado pudo haberse dirigido más acertadamente al supuesto de la. incorporación que hemos visto, pero no al de la fusión, que está en perfecta sintonía no ya con el espíritu, sino incluso con la dicción misma de la propia Ley Reguladora de las Bases del Régimen local. A cambio de la desacertada recomendación de la supresión del párrafo, el Consejo de Estado recomienda que se incorpore el párrafo 3 del artículo 13 de la Ley Reguladora de las Bases del Régimen local, lo que resulta poco afortunado como técnica legislativa, y es esa la razón por la que aparece efectivamente en el actual artículo $5 .^{\circ}, 2$, del Reglamento.

Para la segregación de parte del territorio de uno o varios $\mathrm{Mu}$ nicipios para constituir otro independiente (terminología del Texto Refundido) o constituir nuevos Municipios (terminología del Reglamento) -expresiones similares que por ello no ofrecen mayores dificultades interpretativas-, se exige que existan «motivos permanentes de interés público, relacionados con la colonización interior, explotación de minas, instalación de nuevas industrias, creación de regadíos, obras públicas u otros análogos». Constituye esta expresión una notable simplificación de los preceptos correspondientes del Reglamento derogado de 1952. Parece, sin embargo, superfluo. el párrafo segundo de este mismo artículo $6 .^{\circ}$, según el cual «será necesario que los nuevos Municipios reúnan las condiciones previstas en el artículo $3 .^{\circ}$ ” y que los Municipios de los que se segreguen las partes correspondientes no queden privados de dichas condiciones, ya que es ésta una exigencia de carácter general que se consa- 
gra no sólo en el artículo $8 .^{\circ}, 1$, del Texto Refundido y $3 .^{\circ}$ del nuevo Reglamento, sino también, con carácter básico, y como hemos visto, en el artículo 13, 2, de la Ley Reguladora de las Bases del Régimen local.

Por último, la segregación de parte del territorio de un Municipio para agregarla a otro limítrofe procede «cuando se confundan sus núcleos urbanos como consecuencia del desarrollo urbanístico» y «cuando existan notorios motivos de necesidad o conveniencia económica o administrativa", a tenor de lo establecido en el artículo $8 .^{\circ}$ del Texto Refundido. Más pormenorizadamente, el Reglamento precisa que, a los efectos de la confusión de núcleos urbanos, no constituyen solución de continuidad «los parques, jardines, paseos, avenidas, campos de deporte y zonas residenciales que pudieran existir entre aquéllos». Salvo alguna innovación terminológica, prácticamente el mismo contenido que tenían los preceptos derogados.

El Consejo de Estado, en el antedicho Dictamen, objetó que el precepto no contemplaba con nitidez los supuestos de segregación forzosa y de segregación voluntaria, «sin que en ésta - razonaba el Consejo de Estado- fueran precisas las causas de la primera". Argumentación que no puede compartirse, pues las segregaciones parciales contempladas en este artículo exigen siempre la concurrencia de las causas legalmente previstas, ya que el precepto nada excepciona a tal efecto. Por consiguiente, en estas segregaciones, tanto si son promovidas por los órganos administrativos correspondientes como si lo son por los particulares, se deberá demostrar en el expediente instruido al efecto la existencia de las causas legalmente previstas. Ningún apoyo existe en las nuevas normas para sostener lo contrario, como lo demuestra la exigencia sin excepciones contenida en el artículo 14, 1, b), del Reglamento.

En cualquier caso, la segregación parcial no podrá llevarse a cabo: «a) cuando con ella hubiera de resultar privado de las condiciones exigidas por el artículo $3 .^{\circ}$ para la creación de Municipios; b) cuando el núcleo o poblado de que se trate estuviere unido por calle o zona urbana a otro del Municipio originario". El párrafo a) parece superfluo, por lo que hemos dicho antes en relación con el artículo 13, 2, de la Ley Reguladora de las Bases del Régimen local, y el párrafo segundo ofrece la dificultad interpretativa del concepto de calle o zona urbana que hay que integrar de acuerdo con la legalidad urbanística (régimen del suelo urbano: arts. 78 y siguientes de la Ley del Suelo, y concepto de calle, más confuso, pero que 
puede extraerse del Reglamento General de Carreteras, cuyo artículo $7 .^{\circ}$ dice que no tienen la consideración de carreteras las vías que componen la red interior de comunicaciones municipales, y se entenderá que componen esta red interior las calles, rondas, paseos y cualquier otra vía municipal, siempre que no tengan la consideración legal de travesía ni formen parte de la red arterial de la población).

Carácter general para las segregaciones parciales tiene la exigencia de proceder, junto a la división del territorio, a la de «los bienes, derechos y acciones, deudas y cargas, en función del número. de habitantes y de la riqueza imponible correspondiente al núcleo que se trate de segregar", documentación toda ésta que habrá de integrarse en el expediente de segregación, tal como veremos. Se echan de menos reglas que prevean el régimen inicial de funcionamiento de un nuevo Municipio resultante de una fusión de varios anteriores o incorporación a otro u otros limítrofes (fuera de las normas de contenido electoral contenidas en el art. 16 del Reglamento), aunque ello pueda quedar quizá suplido por la exigencia general prevista en el artículo 14, 2, del propio Reglamento.

\section{D) El procedimiento}

Es en este punto donde las nuevas normas han introducido mayor claridad, si se compara la actual situación con la existente anteriormente, tal como vimos. El iter procedimental se rige por las. siguientes reglas:

\section{a) Iniciación}

Cualquier expediente de alteración podrá iniciarse de oficio por el órgano competente en materia de Administración local de la Comunidad Autónoma o cuando así lo solicite cualquiera de los Ayuntamientos interesados, las Diputaciones provinciales respectivas, la Administración del Estado (a través del Delegado del Gobierno, según la aclaración del Reglamento) u otros órganos de la Comunidad Autónoma que, en razón de sus respectivas competencias, consideren procedente la alteración, precisión esta última que también aparece recogida en el Reglamento y que procede, actualizada, de la previsión del anterior Reglamento, según la cual «otros Ministerios que proyecten obras públicas o de colonización" podrían también 
promover los expedientes de alteración. Creemos que tal previsión podría haberse eliminado en la nueva versión del Reglamento por la anomalía que supone que se equipare a las otras Administraciones públicas a un simple órgano de la misma Comunidad Autónoma que dispone de otras vías para plantear al competente un asunto de esta naturaleza.

También puede iniciarse cualquier expediente de alteración por los Ayuntamientos implicados de forma voluntaria. Y en el caso de aquellos referidos a segregaciones parciales, además, por la mayoría de los vecinos residentes en la parte o partes que hayan de segregarse.

\section{b) Ordenación e instrucción}

Hay que distinguir tres supuestos:

$\left.b^{\prime}\right)$ Alteraciones acordadas por los Ayuntamientos de forma voluntaria.-Se exige acuerdo de los respectivos Ayuntamientos, adoptado con el voto favorable de las dos terceras partes del número de hecho, y, en todo caso, de la mayoría absoluta del número legal de miembros de la Corporación. Esta mayoría reforzada tiene carácter básico y no puede, por consiguiente, modificarse por el legislador autonómico, por el inequívoco contenido del artículo 47, 2, a), de la Ley Reguladora de las Bases del Régimen local, y aunque la Disposición final séptima, $1, a$ ), del Texto Refundido no la mencione.

El expediente así iniciado debe enriquecerse con los documentos exigidos minuciosamente por el artículo 14 del Reglamento, entre los que conviene destacar la fijación de los límites o línea decisoria de los nuevos Municipios resultantes, semillero éste de los conflictos en todas las alteraciones de términos. El expediente, cuando es aprobado por la Comunidad Autónoma, debe contener esta previsión con toda claridad, que ha de ser cumplida, además, antes de iniciar la fase de información pública, pues sólo así los pronunciamientos que se hagan por los interesados podrán estar avalados por un conocimiento exhaustivo del proyecto de alteración. El plazo no será inferior a treinta días.

Procede entonces segundo acuerdo municipal. El Reglamento y también el Texto Refundido exigen la misma mayoría cualificada para adoptar este segundo acuerdo, que hay que entender también 
básico, pues ninguna matización hace al respecto el artículo 47, 2,c), de la Ley Reguladora de las Bases del Régimen local.

Así ultimado el expediente, ha de elevarse al órgano competente de la Comunidad Autónoma, para que ésta emita informe y dé traslado al Consejo de Estado o al órgano consultivo superior del Consejo de Gobierno de la Comunidad Autónoma, allí donde tal órgano esté constituido, así como puesta en conocimiento del expediente a la Administración del Estado (hoy, Ministerio para las Administraciones Públicas). No aclara el precepto qué Ayuntamiento será el encargado de hacer la remisión. Hay que entender que como la alteración del territorio se tramita de forma voluntaria y hay acuerdos favorables, los Ayuntamientos interesados también extenderán. su acuerdo a este punto.

$\left.b^{\prime \prime}\right)$ Alteraciones acordadas por la Comunidad Autónoma.Instruido el expediente, con todas las previsiones contenidas en el artículo 14 (pues el precepto se refiere «a los expedientes", y al estar hecha la referencia en el mismo capítulo I, que corresponde a cualesquiera expedientes, hay que entender lógicamente que abarca a todos), se traslada, por plazo de un mes, a los Municipios y demás Entidades locales interesadas (sobre todo, Diputación provincial) y posterior remisión al Consejo de Estado u órgano consultivo superior de la Comunidad Autónoma, donde ésta exista, así como puesta en conocimiento del expediente a la Administración del Estado (hoy, Ministerio para las Administraciones Públicas). No hay, sin especial razón que lo justifique, trámite de información pública a las poblaciones afectadas.

La audiencia del Ayuntamiento se cumple con la adopción de este acuerdo por mayoría cualificada, que lógicamente no vincula, pues el órgano competente para decidir es el correspondiente de la Comunidad Autónoma (tampoco era vinculante en el sistema anterior, como es lógico, aunque allí también la mayoría exigida era la. cualificada del art. 303 de la Ley de Régimen local y luego de la Ley $40 / 1981$, de 28 de octubre).

$\left.b^{\prime \prime \prime}\right)$ Segregaciones parciales iniciadas por los vecinos.-Puede el expediente de alteración, en fin, iniciarse por los mismos vecinos - por la mayoría de los vecinos residentes en la parte o partes que hayan de segregarse-. El iter procedimental en tal caso. es el siguiente: constitución de una Comisión promotora a la que: 
corresponda reunir la documentación exigida en el artículo 14 (innovación ésta introducida por el nuevo Reglamento); elevación del expediente a los Ayuntamientos; apertura del trámite de información pública por plazo no inferior a treinta días; acuerdo sobre el mismo adoptado con la mayoría cualificada a que se refiere el artículo 47, 2, a), de la Ley Reguladora de las Bases del Régimen local; el expediente así completado se eleva al órgano competente de la Comunidad Autónoma para su posterior dictamen por el Consejo de Estado u órgano consultivo correspondiente. Es de subrayar el hecho de que el acuerdo municipal puede ser desfavorable, es decir, que el expediente puede ser informado de forma negativa por una mayoría cualificada de los Municipios, y ello no es obstáculo para que el expediente se tramite y llegue a la resolución definitiva por el órgano de la Comunidad Autónoma, debido a que tal acuerdo por las razones dichas no tiene carácter vinculante para el órgano decisor.

Como garantía última del derecho de los vecinos promotores a llevar hasta el final el expediente, la Comisión promotora puede remitirlo directamente a la Comunidad Autónoma cuando, en el plazo de dos meses (a contar desde la terminación del período de información pública), el Ayuntamiento no hubiere adoptado acuerdo alguno.

\section{c) Resolución}

La resolución definitiva, si es favorable a la incorporación, fusión o segregación parcial, deberá incorporar el nombre del nuevo Municipio, el núcleo urbano en que haya de fijarse la capitalidad, sus límites territoriales y el contenido de las estipulaciones jurídicas y económicas acordadas por los Ayuntamientos intervinientes para llevar a efecto la alteración. Si éstas han sido objeto de acuerdo previo, ningún problema surgirá para precisar su contenido; pero cuando la alteración del término municipal se produce por decisión de la Comunidad Autónoma (supuesto del art. 9.' del Reglamento) o contra el acuerdo de los Ayuntamientos interesados o su pasividad (supuesto de las segregaciones parciales reguladas en el artículo 13 del Reglamento), el contenido de tales estipulaciones deberá ser hecho por la propia Comunidad Autónoma que resuelve el 
expediente. Así lo exige, de un lado, el artículo 15, d), en relación con el artículo 14, 2, ambos del Reglamento, y, de otro, la necesaria seguridad jurídica que debe acompañar a una operación de esta naturaleza.

Tanto el Texto Refundido como su Reglamento nos dicen que la resolución definitiva se hace por Decreto aprobado por el Consejo de Gobierno de la Comunidad Autónoma. Tal precisión no puede en modo alguno tener carácter de básico, y así lo reconoce la Disposición final séptima, 1, a), del Texto Refundido, por lo que la legislación de las Comunidades Autónomas reguladora de estas materias podrá prever otra forma de aprobación de tales expedientes.

Tales resoluciones deben ser publicadas en el Boletín Oficial del Estado, Boletín de la Comunidad Autónoma y de la Provincia, previsiones las dos últimas que, igualmente, pueden ser alteradas por la legislación de las Comunidades Autónomas.

Tiene carácter básico, sin embargo, el párrafo 3 del artículo 13 (traslado a la Administración del Estado para su inscripción en el Registro estatal de Entidades locales), por lo que se refiere al cambio de denominación, que es el extremo amparado por el artículo 14 de la Ley Reguladora de las Bases del Régimen local, lo que confirma el Texto Refundido, que atribuye a su artículo 11, 3, tal carácter (Disposición final séptima, 1,a). El órgano competente de la Administración del Estado es, lógicamente, en la actualidad, la Dirección General de Administración Local (Decreto 382/1986, de 10 de febrero), dependiente del Ministerio para las Administraciones Públicas. El Registro Central de Cartografía, al que la Dirección General de Administración Local deberá dar conocimiento de los datos relativos al nacimiento y muerte de Municipios, así como de las incidencias territoriales de la vida de éstos, ha sido creado por la Ley $7 / 1986$, de 24 de enero, de Ordenación de la Cartografía (artículo $\left.7 .^{\circ}, 1\right)$.

Sobre la intangibilidad de los límites provinciales y los problemas que ello suscita nos remitimos a lo que se dirá más adelante.

\section{E) La impugnación jurisdiccional}

Al contrario de lo que ocurría en el sistema anterior, donde se plantearon dudas acerca de la recurribilidad o no de los acuerdos del Consejo de Ministros en esta materia, ninguna existe en la ac- 
tualidad por la aplicación general de la cláusula de tutela judicial efectiva contenida en el artículo 24 de la Constitución.

El Juez del orden contencioso-administrativo, que sería el Tribunal Superior de Justicia en la Comunidad Autónoma, de acuerdo con la Ley 6/1985, de 1 de julio, Orgánica del Poder Judicial, podrá entrar a valorar: a) la corrección del procedimiento que ha culminado en la alteración o denegación, en su caso, de la alteración proyectada; b) la existencia de las causas que puedan dar lugar a la alteración o la inexistencia de las mismas, que, como conceptos jurídicos indeterminados, pueden ser revisados por el Juez, si bien permanece en manos de la Administración un ámbito de valoración que no es revisable por el Juez (14) y que el legislador se ha cuidado

(14) Se trata del Beurteilungsspielraum de la doctrina alemana, que, como la Jurisprudencia alemana más reciente ha matizado, sólo de manera limitada, es revisable por el Juez: existe un "ámbito de enjuiciamiento» no cuando se aplica cualquier concepto indeterminado, quiere otorgar a la Administración ese ámbito de decisión (prerrogativa de enjuiciamiento) que sólo parcialmente es reseñable por el Juez; véase MAYRRKoPP: Allgemeines Verwaltungsrecht, 5.` ed., 1985, págs. 156 y sigs. En Francia, la doctrina y la Jurisprudencia han abordado el problema de los límites del control judicial sobre los motivos de hecho, partiendo del principio de que, correspondiendo al Juez el control de legalidad - no así el de oportunidad-, aquél debe cesar donde la legalidad termina. La cuestión se centra en saber dónde termina la legalidad y dónde empieza la oportunidad, cuando la determinación del supuesto de hecho precisa de un acto de apreciación subjetiva de la Administración. Comoquiera que la apreciación realizada por la Administración de los motivos de hecho, que, en un principio no es discrecional, tiene, sin embargo, una estrecha relación con el juicio de oportunidad, con el que, en casos límite, puede llegar a confundirse, la frontera entre la legalidad y la oportunidad se convierte así en algo gradual, cuya delimitación va a depender del modo en que aquella apreciación haya sido realizada. Es precisamente cuando, por no existir parámetros objetivos disponibles, tiene que hacerse aquella calificación en base fundamentalmente a "criterios subjetivos de apreciación», cuando debe detenerse el control judicial; podrá únicamente ser sobrepasado cuando la Administración, al realizar su apreciación de los hechos, hubiere incurrido en «error manifiesto», es decir, aquel que "saute aux yeux sans qu'il soit besoin d'être un expert très avertis. Vid., entre otros, Jean RIvero: Droit Administratif, Themis, 1985, páginas 593 y sigs. Vid. C.E. 29 mars 1968, Sté. du lotissement de la plage de Pampelonne. A.J., 1968, pág. 341. La Jurisprudencia de nuestro Tribunal Supremo percibe esta situación en la Sentencia de 15 de junio de 1984; sólo percibe, pues llega a unas conclusiones poco compatibles con la premisa de la que parte y, además, lo hace con un lenguaje de una gran imprecisión técnica. Se trataba de la segregación de un Municipio de la Provincia de Castellón de la Plana, de uno de sus núcleos de población que así lo había solicitado. El Tribunal Supremo ordena a la Administración "la constitución como Municipio del núcleo de población», si bien ello se hace porque el acuerdo del Consejo de Ministros que denegó la segregación «aparece sumido en el más absoluto arcano», por lo que, aun propugnando el Tribunal la libertad de elección del Gobierno entre varias alternativas, «mal puede propugnarse el formal reconocimiento de su libertad y el refrendo de una decisión radicalmente contrapuesta a la solución abonada por todos los datos en presencia y por el carácter unánime de los órganos consultivos de la propia Administración». Debemos pensar que el Tribunal se ha visto en este caso en la necesidad de desmontar un acuerdo en Consejo de Ministros, poco claro en cuanto a sus motivaciones; pero que otro hubiera sido el resultado del control judicial si el Ejecutivo hubiera razonado adecuada y documentalmente su negativa. 
de preservar al utilizar inequívocamente el verbo "podrán» (así, artículos $4 .^{\circ}$ y siguientes del Texto Refundido y del Reglamento).

\section{F) La falta de previsión del acomodo de materias complementarias}

Un importante vacío se detecta en esta regulación, que sólo en parte podrá ser cubierta por la legislación autonómica de desarrollo: nos referimos a la falta de previsión legal sobre la necesidad de acomodar los servicios públicos y la legislación complementaria que resulte afectada en los supuestos de alteración de términos municipales, a excepción de las consecuencias electorales, para las que sí se arbitra una solución en el artículo 16 del Reglamento (que incorpora, por cierto, el contenido del Real Decreto 693/1981, de 13 de marzo). Tal es el caso de los servicios sanitarios, de la seguridad social, de la organización judicial, de las fuerzas y cuerpos de seguridad del Estado, de las notarías o los registros de la propiedad, etcétera. En todos los supuestos en que la Comunidad Autónoma autorice una alteración municipal, bien en el marco de un expediente administrativo concreto, bien como consecuencia de una operación llevada a cabo por ley, deberá prever la acomodación de estos servicios públicos, algunos de los cuales pueden entrar en el ámbito de sus competencias; pero otros, los más, están en la disponibilidad del Estado, por lo que será necesario convenir con éste la nueva estructura de los servicios públicos afectados. Ambas operaciones deben ser realizadas de forma simultánea, para que no padezcan las prestaciones concretas que reciben los ciudadanos.

\section{G) Los enclaves municipales}

Su existencia, debida a razones históricas, geográficas, económicas o de otra índole -entre las que no deben descartarse las atribuidas a meros errores de cartografía-, está reconocida por el Reglamento de Población y Demarcación Territorial de las Entidades locales de 11 de julio de 1986, el cual, siguiendo una línea ya tradicional en nuestro Derecho (15), afirma en su artículo $1 .^{\circ}, 3$, que «el término municipal está formado por territorios continuos, pero po-

(15) Vid. artículo 3 del Real Decreto de 30 de noviembre de 1833, artículo 1 del Real Decreto de 25 de septiembre de 1863 y artículo 2-2 del Reglamento de Población y Demarcación Territorial de 17 de mayo de 1952. 
drán mantenerse las situaciones de discontinuidad que estén reconocidas actualmente».

Los enclaves suponen, pues, una excepción al principio de continuidad territorial de los términos municipales, por lo que su existencia necesita ser probada, ya que en otro caso prevalecerá la presunción iuris tantum de que los términos municipales son territorios continuos, como ha sostenido el Tribunal Supremo en Sentencias de 9 de diciembre de 1957 y de 23 de enero de 1969 (16).

Estas situaciones de discontinuidad son numerosas (17) y variadas (18), y su corrección ha sido, desde el primer momento, una preocupación constante que ha chocado con frecuencia con la reacción de los opositores a toda alteración del statu quo vigente (19). Con todo, la racionalización de la división territorial hace aconsejable una política que tienda a la eliminación de dichas anomalías, y en cuya instrumentación habrán de jugar un papel importante determinadas modalidades de alteración de términos municipales, como la incorporación y fusión.

(16) Vid. Aurelio Guatta: División territorial y descentralización, Madrid, 1975, página 50.

(17) Vid. «Enclaves territoriales provinciales», inserto en el Repertorio de la Vida Local de España de 1954, donde se realiza, a iniciativa del Instituto de Estudios de Administración Local, un catálogo de los enclaves administrativos de las Corporaciones provinciales de España. Vid. también Ignacio Ballester Ros, que, en su trabajo "Los enclaves municipales en España», REVISTA DE Estudios DE LA VIDA Local, 1968, efectúa una relación más extensa, al tiempo que reconoce que un examen total de los enclaves entidades de población precisaría un estudio más profundo que contase con la colaboración de los Ayuntamientos.

(18) Ignacio BALLESTER Ros sistematiza de la siguiente forma la situación real: A) Municipios enclavados en Provincia distinta de aquélla a que pertenecen. B) Municipios enclavados en partidos judiciales distintos de aquél a que pertenecen. C) Entidades de población, no Municipios, enclavados en Provincia distinta de aquélla a que pertenece el Municipio de que forma parte. D) Entidades de población, no Municipios, enclavadas en partidos judiciales distintos de aquéllas a que pertenece el Municipio de que forma parte. E) Entidades de población, no Municipios, enclavados entre Municipios, ninguno de los cuales es aquél a que pertenecen. F) Comunidades de bosques, pastos o tierras poseídas en común por varios Municipios. G) Términos municipales no deslindados. Vid. "Los enclaves...», ob. cit., pág. 405.

(19) Tal es lo sucedido con la incorporación a Alava del enclave de Orduña por Real Orden de 13 de mayo de 1843, que hubo de ser reintegrado a la Provincia de Vizcaya el 6 de septiembre siguiente como consecuencia de la reacción que produjo la medida. Ya en nuestros días merecen citarse los acuerdos de los Ayuntamientos de Puebla de Arganzón y Condado de Treviño, de 17 de octubre y 26 de enero de 1980, respectivamente, de incorporarse dichos enclaves a la Provincia de Alava y a la Comunidad Autónoma del País Vasco, y que han motivado la Sentencia del Tribunal Constitucional de 14 de julio de 1986, desestimando los recursos de inconstitucionalidad promovidos por el Gobierno y el Parlamento vascos contra la Disposición transitoria $7 .^{\mathrm{a}}, 3$, de la Ley Orgánica 4/83, de 25 de febrero, del Estatuto de Autonomía de Castilla-León. 


\section{H) El deslinde de los términos municipales}

Según hemos dicho con anterioridad, la fijación de los límites de los Municipios debe quedar establecida con nitidez en el momento de la aprobación del correspondiente expediente (así lo dice con toda claridad el art. 15; $c$, del Reglamento). No debe olvidarse que es éste con frecuencia el aspecto central de toda alteración, como puede comprobarse a través de la jurisprudencia del Tribunal Supremo. La fijación de límites no constituye un expediente señalado, sino, por el contrario, una parte, y sustantiva, por cierto, del expediente general de la alteración.

Sólo, pues, de forma complementaria analizamos aquí muy sumariamente el procedimiento de deslinde tal como viene regulado en el nuevo Reglamento, aun a sabiendas de su carácter incompleto, pues un estudio más minucioso exigiría mayores precisiones y, sobre todo, un análisis de la jurisprudencia del Tribunal Supremo, muy abundante en este punto, y al que conscientemente renunciamos, por no constituir el objeto específico de esta investigación.

Cada uno de los Ayuntamientos deberá nombrar una Comisión formada por las personas a que alude el artículo 17 del Reglamento, a las que corresponderá hacer la propuesta inicial. Si hay avenencia, tal propuesta será aceptada por los Ayuntamientos correspondientes, por cierto con el voto favorable de las dos terceras partes del número de hecho y, en todo caso, de la mayoría absoluta legal de miembros de la Corporación, según el artículo 47, 2, c), de la Ley Reguladora de las Bases del Régimen local (lo que parece excesivo), y con posterioridad se comunica a la Comunidad Autónoma y al Instituto Geográfico Nacional.

Si tal avenencia no se produjera, la decisión del conflicto corresponde a la Comunidad Autónoma, previo informe del Instituto Geográfico Nacional y dictamen del Consejo de Estado $\mathbf{u}$ órgano consultivo de la misma, y de ella se dará traslado al Ministerio para las Administraciones Públicas. Ninguna precisión consta, por cierto, acerca del problema que pueden plantear Municipios que se encuentran en Comunidades Autónomas distintas.

Por último, el artículo 25 nos dice enigmáticamente que «la determinación de los límites de los Municipios o Entidades locales de ámbito territorial inferior al Municipio, creados al amparo de lo dispuesto en los artículos $3 .^{\circ}$ y $60^{\circ}$ de este Reglamento, correspon- 
LA ALTERACION DE TERMINOS MUNICIPALES EN EL NUEVO DERECHO LOCAL

derá a la Comunidad Autónoma respectiva». Este precepto resulta poco afortunado, pues es evidente que, de un lado, la determinación de los límites de un Municipio cuando éste ha sido creado en el marco de un expediente de alteración de términos municipales corresponde, como ya sabemos, a la Comunidad Autónoma, lo que no era necesario repetir, y, de otro, los preceptos citados para nada se refieren a las Entidades locales de ámbito territorial inferior al Municipio, que tienen un régimen distinto que en su momento veremos. Se trata, sin duda, de un error. 
REALA-1986, núm. 232. SOSA WAGNER, FRANCISO. LA ALTERACION DE TERMINOS MUNICIPAL...

REALA-1986, núm. 232. SOSA WAGNER, FRANCISO. LA ALTERACION DE TERMINOS MUNICIPAL... 